\title{
Renal transplantation outcomes in obese patients: a French cohort-based study
}

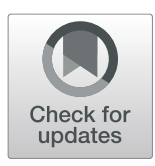

\author{
Y. Foucher ${ }^{1,2^{*}}$ (D) M. Lorent ${ }^{1,2,3}$, L. Albano ${ }^{4}$, S. Roux ${ }^{1}$, V. Pernin ${ }^{5}$, M. Le Quintrec ${ }^{5}$, C. Legendre ${ }^{6}$, F. Buron? \\ E. Morelon ${ }^{7}$, S. Girerd ${ }^{8}$, M. Ladrière ${ }^{8}$, D. Glotz ${ }^{9}$, C. Lefaucher ${ }^{9}$, C. Kerleau ${ }^{2,3}$, J. Dantal 2,3,10, J. Branchereau 2,3,10, \\ M. Giral ${ }^{2,3,10}$ and for the DIVAT consortium
}

\begin{abstract}
Background: Whilst there are a number of publications comparing the relationship between body mass index (BMI) of kidney transplant recipients and graft/patient survival, no study has assessed this for a French patient cohort.

Methods: In this study, cause-specific Cox models were used to study patient and graft survival and several other time-to-event measures. Logistic regressions were performed to study surgical complications at 30 days posttransplantation as well as delayed graft function.

Results: Among the 4691 included patients, 747 patients were considered obese with a BMl level greater than $30 \mathrm{~kg} /$ $\mathrm{m}^{2}$. We observed a higher mortality for obese recipients ( $\left.H R=1.37, p=0.0086\right)$ and higher risks of serious bacterial infections ( $H R=1.24, p=0.0006)$ and cardiac complications ( $H R=1.45, p<0.0001)$. We observed a trend towards death censored graft survival ( $H R=1.22, p=0.0666)$ and no significant increased risk of early surgical complications.
\end{abstract}

Conclusions: We showed that obesity increased the risk of death and serious bacterial infections and cardiac complications in obese French kidney transplant recipients. Further epidemiologic studies aiming to compare obese recipients versus obese candidates remaining on dialysis are needed to improve the guidelines for obese patient transplant allocation.

Keywords: Obesity, Kidney transplantation, Cohort study, Post-transplant outcomes

\section{Background}

According to the World Health Organization report [1], obesity has tripled worldwide since 1975 and 650 million adults were classified as obese in 2016. Obesity is defined by a body mass index (BMI) greater than or equal to $30 \mathrm{~kg} / \mathrm{m}^{2}$. Obesity is associated with increased rates of cardiovascular diseases, diabetes, musculoskeletal disorders and cancer [2]. Obesity also increases the risk for chronic kidney disease and its progression to End-Stage Renal Disease (ESRD) [3]. In the North-American patients, obesity rates have increased by 33\% from 1995 to

\footnotetext{
* Correspondence: Yohann.Foucher@univ-nantes.fr

${ }^{1}$ INSERM UMR 1246 - SPHERE, Nantes University, Tours University, Nantes, France

${ }^{2}$ Centre Hospitalier Universitaire de Nantes, Nantes, France

Full list of author information is available at the end of the article
}

2002 [4]. In France, the prevalence of obesity is around $21 \%$ in patients undergoing hemodialysis, whilst an increase in survival for ESRD patients with a high-level BMI have been reported $[5,6]$.

In ERSD patients, transplantation is recognized as the best long-term treatment compared to dialysis in terms of both the quality and the quantity of life $[7,8]$. Unfortunately, obesity may be an obstacle to transplantation access, with the waiting time on dialysis of obese patients depending on center/country practices and guidelines [9-11]. In France, obese patients have a transplantation likelihood lower than nonobese ones [12]. Several reasons can explain this situation, especially the increased risk of complications after transplantation such as wound healing, delayed graft function, hospital readmissions, or new-onset diabetes [13, 14]. In contrast, the literature remains controversial concerning graft and patient

(C) The Author(s). 2021 Open Access This article is licensed under a Creative Commons Attribution 4.0 International License, which permits use, sharing, adaptation, distribution and reproduction in any medium or format, as long as you give appropriate credit to the original author(s) and the source, provide a link to the Creative Commons licence, and indicate if changes were made. The images or other third party material in this article are included in the article's Creative Commons licence, unless indicated otherwise in a credit line to the material. If material is not included in the article's Creative Commons licence and your intended use is not permitted by statutory regulation or exceeds the permitted use, you will need to obtain permission directly from the copyright holder. To view a copy of this licence, visit http://creativecommons.org/licenses/by/4.0/ The Creative Commons Public Domain Dedication waiver (http://creativecommons.org/publicdomain/zero/1.0/) applies to the data made available in this article, unless otherwise stated in a credit line to the data. 
outcomes. Several recent meta-analyses illustrate this debate [15-19].

Nicoletto et al. [15] reported that the only consequence of obesity was a higher incidence of Delayed Graft Function (DGF). Lafranca et al. [16] showed no significant difference between obese and non-obese patients in terms of patient and graft survival. In contrast, the authors observed a protective relationship between high-level BMI and 3-year mortality. Hill et al. [17] reported no significant correlation between obesity and patient survival, a weak relationship with death-censored graft survival, and a correlation with DGF. Sood et al. [18] reported that obese patients had an increased risk of DGF, acute rejection, death and death-censored graft failure.

The literature based on studies from European countries is weak or underrepresented, and most studies have assessed only North-American patients [15-18]. More specifically, no study based on a large cohort of French patients has been performed, with the largest including only 250 patients [19]. In this context, the aim of our study was to analyze the relationships between obesity and posttransplant outcomes by using a large and multicentric cohort of French kidney transplanted recipients.

\section{Methods}

\section{Studied population}

Data were extracted from the French prospective DIVAT (Données Informatisées et VAlidées en Transplantation) cohort (www.divat.fr, French Research Ministry: RC12_0452, last agreement No 13334, No CNIL for the cohort: 891735) composed of kidney transplant recipients followed in Nantes, Paris (Necker and Saint-Louis), Montpellier, Nancy, Lyon, and Nice University Hospitals. This represents around one third of the kidney transplantations performed in France. The study was performed in accordance with the Declaration of Helsinki and we obtained the agreement of the DIVAT Scientific Council. The quality of the DIVAT data bank is validated by a center audit. The participants gave written informed consent. The included patients were older than 18 years with a BMI-level higher than $18.5 \mathrm{~kg} / \mathrm{m}^{2}$ at the time of their transplantation. Only first kidney transplants from deceased donors were considered. Multiple organ transplant recipients were not included. The study was limited to transplantations performed from January 2005 to December 2016 to respect current practices. Patients were considered in the obese group if their BMI at transplantation was higher than $30 \mathrm{~kg} / \mathrm{m}^{2}$.

\section{Available data at transplantation}

Donor variables extracted from the database were age, sex, last serum creatininemia, donor cause of death and type (living or deceased including heart or non-heart beating donors), and expanded donor criteria (ECD).$^{20}$ Recipient characteristics at baseline were age, sex, blood group, initial recurrent causal nephropathy following transplantation (the following were considered as possibly recurrent: glomerulosclerosis, serious nephrotic syndrome with focal sclerosis, IgA nephropathy (Berger's disease), dense deposit disease, glomerulonephritis, Wegener's granulomatosis, Lupus erythematosus, Henoch-Schoenlein purpura, Goodpasture's syndrome, systemic sclerosis (scleroderma), haemolytic uraemic syndrome, multi-system disease), renal disease, comorbidities prior to transplantation (diabetes, hypertension, dyslipidemia, neoplasia, cardiovascular history (cardiopathy and cardiomyopathy, cardiac insufficiency, coronaropathy, cardiac rhythm disorder, cardiac valvopathy, cardiac valvular prothesis, cardiac conduction disorder, pacemaker, cardiogenic shock or collapses, pulmonary hypertension, cerebrovascular accident (stroke or bleeding), peripheral arteriopathy, or venous thrombo-embolism), duration on waiting list before transplantation, type of dialysis before transplantation (peritoneal, hemodialysis or pre-emptive) and anti- Human Leucocyte Antigen (HLA) class I or anti-class II immunization before transplantation. Transplantation parameters were cold ischemia time, number of HLA (A + $\mathrm{B}+\mathrm{DR})$ incompatibilities and induction therapy. For donor and recipients, Epstein-Barr Virus (EBV) and Cytomegalovirus (CMV) serology were also extracted.

\section{Post-transplantation outcomes}

The long-term outcomes were the patient and graft survival (defined by the time between the transplantation and the first event between return to dialysis, pre-emptive retransplantation or death), graft survival (death with a functioning graft were right-censored) and patient survival (return to dialysis or pre-emptive re-transplantation were rightcensored). The mid-term outcomes were the time to the first biopsy-proven acute rejection episode, cardiac complication (cardiopathy and cardiomyopathy, cardiac insufficiency, coronaropathy, cardiac rhythm disorder, cardiac valvopathy, cardiac valvular prothesis, cardiac conduction disorder, pacemaker, cardiogenic shock or collapses, pulmonary hypertension), serious bacterial infection (endocarditis, mediastinitis, myocarditis, valve prosthesis infection, pericarditis, dermohypodermatitis, colitis, biliary tract infection, pancreatitis, peritonitis, salpingitis, hepatitis, liver abscess, meningoencephalitis, meningoradiculitis, brain abscess, pulmonary abscess, pleural infection, pneumonia, osteoarthritis, or pyelonephritis) and cancer (solid, skin and PostTransplantation Lymphoproliferative Disorders - PTLD). The short-term outcomes were the surgical or renal vascular complications occurring within the first month posttransplantation. Two sub-group analyses were performed to study DGF occurrence (defined by the need for dialysis in the first week post-transplantation) and the time to New Onset Diabetes After Transplantation (NODAT). The analysis of DGF excluded the pre-emptive patients and those on 
peritoneal dialysis (because one cannot measure a DGF in this subpopulation), whereas the analysis of the time to NODAT excluded the diabetic patients prior to transplantation.

\section{Statistical analyses}

The characteristics between the two groups of interest (obese and non-obese recipients) were compared using Chi-square tests for categorical variables and Student ttests for continuous variables. Survival curves were obtained by using the Kaplan-Meier estimator. To further compare the outcomes and to consider possible confounders, multivariate logistic regressions were used for binary outcomes and cause-specific Cox models for timesto-event. Variables significantly associated with both the outcome and the obesity status in univariate regressions were retained $(p<0.20)$ in the multivariable models. We did not consider the treatments as covariates since they constituted consequences of the obesity status. The consideration of such covariates on the pathway would have been associated with over-adjusted results. The loglinearity assumption was automatically checked: rejection of this assumption occurred when the Bayesian Information Criterion decreased using natural spline transformation compared to the inclusion of the covariate in its natural scale. In cases of violation, variables were categorized. Hazard proportionality was checked by plotting logminus-log survival curves according to the two groups of interest and studying the Schoenfeld residuals. The collinearity of the retained covariates was investigated, and no issue was identified. All the models were also centeradjusted (baseline hazard stratification for the Cox regressions). Statistical analyses were performed using PlugStat@ (www.labcom-risca.com).

\section{Results \\ Cohort description}

The characteristics of the 4691 patients included in the study are described in Tables 1 and 2. Three thousand nine hundred forty-four patients were in the non-obese group (NOG, 84.1\%) versus 747 in the obese group (OG, $15.9 \%)$. One hundred thirteen patients had a BMI $>35$ $\mathrm{kg} / \mathrm{m}^{2}$. In the NOG, the mean BMI was $24.2( \pm 2.9) \mathrm{kg} /$ $\mathrm{m}^{2}$ (ranging from 18.6 to 30.0 ) versus $32.8( \pm 2.5) \mathrm{kg} / \mathrm{m}^{2}$ in the OG (ranging from 30.1 to 50.3 ). As expected, several characteristics at transplantation differed between the two groups. The prevalence of recipients older than 55 years was $60.4 \%$ in the OG versus $50.3 \%$ in the NOG $(p<0.0001)$. The percentage of male recipients was lower in the OG (55.4\% versus 65.0, $p<0.0001)$, but the prevalence of patients with diabetes and history of dyslipidemia was higher (38.3\% versus $16.2 \%, p<0.0001$; and $56.0 \%$ versus $38.4 \%, p<0.0001)$. Obese patients were more likely to receive ECD grafts (52.3\% versus 46.1\%, $p=0.0021$ ).

During the follow-up, 462 patients died with a functioning graft (including 101 in the OG), 614 returned to dialysis (including 118 in the OG) and 12 were preemptive re-transplantations (including 1 in the OG). Median follow-up time for the cohort was 4.0 years (range from 0.0 to 13.2 ).

\section{Graft and/or patient survival}

The patient and graft survival curves are presented in Fig. 1. The survival was $44 \%$ (95\%CI from 38 to $52 \%$ ) at 10 years post-transplantation in the OG versus $58 \%$ (95\%CI from 55 to $61 \%$ ) in the NOG. As illustrated in Table S1, the corresponding adjusted HR (Hazard Ratio) of the obese versus non-obese group was 1.28 (95\%CI from 1.09 to $1.50, p=0.0021)$ : an obese patient has a 1.28 -fold increased risk of death or return to dialysis compared to a non-obese patient with similar risk factors at transplantation. When deaths were censored, the adjusted HR of graft failure was 1.22 (Table S2, 95\%CI from 0.99 to $1.51, p=0.0666$ ). When graft failures were censored, the adjusted HR of death with a functioning graft was 1.37 (Table S3, 95\%CI from 1.08 to $1.72, p=$ 0.0086). These two cause-specific results illustrate that the worse prognosis for obese recipients in terms of patient and graft survival was related to excess mortality. All the results in terms of adjusted relative effects are summarized in Fig. 2.

In addition, we performed the following comparisons to evaluate if $30 \mathrm{~kg} / \mathrm{m}^{2}$ corresponded to a sudden threshold in the risk of graft failure: $<25.0$ versus $25.0-27.5$, 25.0-27.5 versus $27.5-30.0,27.5-30.0$ versus $30.0-32.5$, and $30.0-32.5$ versus $>32.5 \mathrm{~kg} / \mathrm{m} 2$. As shown in Figure $\mathrm{S} 1$, no such threshold was identified. Finally, we explored the change in the obesity effect according to the recipient age (Figure S2). In recipients $<55$ years old, the $\mathrm{HR}$ of obese versus non-obese patients was 1.06 (95\%CI from 0.77 to 1.45 ), 1.04 (95\%CI from 0.73 to 1.47), and 1.10 (95\%CI from 0.60 to 2.03 ) for patient and graft, graft, and patient survival, respectively. The corresponding estimations were 1.40 (95\%CI from 1.17 to 1.67), 1.26 (95\%CI from 0.96 to 1.65 ), and 1.46 (95\%CI from 1.15 to 1.87 ), highlighting the higher impact of obesity in older recipients.

\section{Bacterial infection, neoplasia, cardiac complications and acute rejection episodes}

The cumulative probability of bacterial infection at 5 years post-transplantation was 0.44 (95\%CI from 0.42 to 0.46 ) in the NOG versus 0.55 (95\%CI from 0.50 to 0.58 ) in the OG. The corresponding adjusted HR was 1.24 (Table S4, $95 \% \mathrm{CI}$ from 1.10 to $1.40, p=0.0006$ ), meaning a 1.2 -fold increase in the risk of bacterial infection for obese 
Table 1 Description of the recipients' characteristics according to obesity status

\begin{tabular}{|c|c|c|c|c|c|c|c|c|c|c|}
\hline & \multicolumn{3}{|c|}{$\begin{array}{l}\text { Whole sample } \\
(n=4691)\end{array}$} & \multicolumn{3}{|c|}{$\begin{array}{l}\text { Non-obese } \\
(n=3944)\end{array}$} & \multicolumn{3}{|c|}{$\begin{array}{l}\text { Obese } \\
(n=747)\end{array}$} & \multirow[t]{2}{*}{$p$-value } \\
\hline & NA & $\mathrm{n}$ & $\%$ & NA & $\mathbf{n}$ & $\%$ & NA & n & $\%$ & \\
\hline Male & 0 & 2977 & 63.5 & 0 & 2563 & 65.0 & 0 & 414 & 55.4 & $<0.0001$ \\
\hline Recurrent causal nephropathy $(*)$ & 1 & 1114 & 23.8 & 1 & 983 & 24.9 & 0 & 131 & 17.5 & $<0.0001$ \\
\hline Causal nephropathy & 1 & & & 1 & & & 0 & & & $<0.0001$ \\
\hline Diabetes & & 569 & 12.1 & & 392 & 9.9 & & 177 & 23.6 & \\
\hline Glomerulopathy & & 935 & 19.8 & & 823 & 20.8 & & 112 & 15.0 & \\
\hline Other & & 2252 & 47.8 & & 1963 & 49.5 & & 289 & 38.6 & \\
\hline Tubulointerstitial nephritis & & 414 & 8.8 & & 352 & 8.9 & & 62 & 8.3 & \\
\hline Vascular disease & & 540 & 11.5 & & 431 & 10.9 & & 109 & 14.6 & \\
\hline Preemptive transplantation & 8 & 450 & 9.6 & 8 & 395 & 10.0 & 0 & 55 & 7.4 & 0.0231 \\
\hline Peritoneal dialysis & 8 & 454 & 9.7 & 8 & 398 & 10.1 & 0 & 55 & 7.4 & 0.0240 \\
\hline History of diabetes & 0 & 923 & 19.7 & 0 & 637 & 16.2 & 0 & 286 & 38.3 & $<0.0001$ \\
\hline History of hypertension & 0 & 3949 & 84.2 & 0 & 3301 & 83.7 & 0 & 648 & 86.7 & 0.0362 \\
\hline History of vascular disease & 0 & 837 & 17.8 & 0 & 696 & 17.6 & 0 & 141 & 18.9 & 0.4214 \\
\hline History of cardiac disease & 0 & 1355 & 28.9 & 0 & 1095 & 27.8 & 0 & 260 & 34.8 & 0.0001 \\
\hline History of cardiovascular disease & 0 & 1806 & 38.5 & 0 & 1475 & 37.4 & 0 & 331 & 44.3 & 0.0004 \\
\hline History of malignancy & 0 & 476 & 10.1 & 0 & 406 & 10.3 & 0 & 70 & 9.4 & 0.4435 \\
\hline History of dyslipidemia & 0 & 1934 & 41.2 & 0 & 1516 & 38.4 & 0 & 418 & 56.0 & $<0.0001$ \\
\hline History of B or C hepatitis & 0 & 250 & 5.3 & 0 & 224 & 5.7 & 0 & 26 & 3.5 & 0.0142 \\
\hline Positive CMV serology & 47 & 3028 & 65.2 & 40 & 2515 & 64.4 & 7 & 513 & 69.3 & 0.0102 \\
\hline Positive EBV serology & 62 & 4488 & 97.0 & 53 & 3765 & 96.8 & 9 & 723 & 98.0 & 0.0806 \\
\hline Positive class I anti-HLA antibodies & 378 & 1369 & 31.7 & 318 & 1145 & 31.6 & 60 & 224 & 32.6 & 0.5956 \\
\hline Positive class II anti-HLA antibodies & 432 & 1223 & 28.7 & 360 & 1033 & 28.8 & 72 & 190 & 28.1 & 0.7224 \\
\hline Blood group & 3 & & & 1 & & & 2 & & & 0.4660 \\
\hline A & & 2018 & 43.0 & & 1695 & 43.0 & & 323 & 43.4 & \\
\hline$A B$ & & 221 & 4.7 & & 178 & 4.5 & & 43 & 5.8 & \\
\hline B & & 533 & 11.4 & & 448 & 11.4 & & 85 & 11.4 & \\
\hline 0 & & 1916 & 40.9 & & 1622 & 41.1 & & 294 & 39.5 & \\
\hline HLA A-B-DR incompatibilities $\geq 4$ & 43 & 720 & 15.5 & 34 & 610 & 15.6 & 9 & 110 & 14.9 & 0.6318 \\
\hline ABO incompatible transplants & 0 & 1 & 0.1 & 0 & 6 & 0.2 & 0 & 1 & 0.1 & 1.0000 \\
\hline Depleting induction & 0 & 2505 & 53.4 & 0 & 2060 & 52.2 & 0 & 445 & 59.6 & 0.0002 \\
\hline \multicolumn{11}{|l|}{ Maintenance therapy } \\
\hline Calcineurin inhibitors & 0 & 4611 & 97.9 & 0 & 3873 & 97.8 & 0 & 738 & 98.5 & 0.2240 \\
\hline Corticosteroids & 0 & 4832 & 93.0 & 0 & 3683 & 93.0 & 0 & 699 & 93.3 & 0.7775 \\
\hline \multirow[t]{2}{*}{ Age $\geq 55$ years } & 0 & 2435 & 51.9 & 0 & 1984 & 50.3 & 0 & 451 & 60.4 & $<0.0001$ \\
\hline & NA & mean & sd & NA & mean & sd & NA & mean & sd & $p$-value \\
\hline Waiting list (months) & 108 & 25.9 & 22.7 & 91 & 25.9 & 22.8 & 17 & 25.6 & 21.7 & 0.6865 \\
\hline Age (years) & 0 & 53.5 & 13.2 & 0 & 52.9 & 13.5 & 0 & 56.2 & 11.2 & $<0.0001$ \\
\hline Cold ischemia time (hours) & 18 & 18.1 & 7.4 & 13 & 18.1 & 7.5 & 5 & 18.3 & 7.1 & 0.4490 \\
\hline
\end{tabular}

Abbreviations: HLA Human Leucocyte Antigen, CMV Cytomegalovirus, EBV Epstein-Barr Virus

patients. The cumulative probability of cancer at 5 years post-transplantation was 0.16 ( $95 \% \mathrm{CI}$ from 0.15 to 0.18 ) in the NOG versus 0.14 (95\%CI from 0.11 to 0.18 ) in the OG. In contrast to bacterial infections, obese patients had a lower risk of cancer compared with non-obese patients (Table S5, adjuster $\mathrm{HR}=0.73,95 \% \mathrm{CI}$ from 0.57 to 0.94 , $p=0.0160)$. The cumulative probability of cardiac complication at 5 years post-transplantation was $0.23(95 \% \mathrm{CI}$ 
Table 2 Description of the donors' characteristics according to obesity status

\begin{tabular}{|c|c|c|c|c|c|c|c|c|c|c|}
\hline & \multicolumn{3}{|c|}{$\begin{array}{l}\text { Whole sample } \\
(n=4691)\end{array}$} & \multicolumn{3}{|c|}{$\begin{array}{l}\text { Non-obeses } \\
(n=3944)\end{array}$} & \multicolumn{3}{|c|}{$\begin{array}{l}\text { Obeses } \\
(n=747)\end{array}$} & \multirow[t]{2}{*}{$p$-value } \\
\hline & NA & $\mathbf{n}$ & $\%$ & NA & $\mathbf{n}$ & $\%$ & NA & $\mathbf{n}$ & $\%$ & \\
\hline Male & 5 & 2766 & 59.0 & 3 & 2320 & 58.9 & 2 & 446 & 59.9 & 0.6117 \\
\hline ECD & 53 & 2186 & 47.1 & 48 & 1798 & 46.1 & 5 & 388 & 52.3 & 0.0021 \\
\hline Non heart-beating & 0 & 204 & 4.3 & 0 & 180 & 4.6 & 0 & 24 & 3.2 & 0.0969 \\
\hline Cerebro-Vascular cause of death (Stroke or bleeding) & 12 & 2533 & 54.1 & 10 & 2105 & 53.5 & 2 & 428 & 57.4 & 0.0477 \\
\hline Hypertension & 192 & 1409 & 31.3 & 166 & 1174 & 31.1 & 26 & 235 & 32.6 & 0.4203 \\
\hline Positive CMV serology & 13 & 2584 & 55.2 & 11 & 2165 & 55.0 & 2 & 419 & 56.2 & 0.5477 \\
\hline Positive EBV serology & 42 & 4461 & 96.0 & 34 & 3743 & 95.7 & 8 & 718 & 97.2 & 0.0704 \\
\hline Blood group & 3 & & & 3 & & & 0 & & & 0.5152 \\
\hline A & & 2021 & 43.1 & & 1696 & 43.0 & & 325 & 43.5 & \\
\hline$A B$ & & 195 & 4.2 & & 157 & 4.0 & & 38 & 5.1 & \\
\hline B & & 486 & 10.4 & & 408 & 10.4 & & 78 & 10.4 & \\
\hline 0 & & 1986 & 42.4 & & 1680 & 42.6 & & 306 & 41.0 & \\
\hline \multirow[t]{2}{*}{ Age $\geq 55$ years } & 15 & 2509 & 53.7 & 14 & 2062 & 52.5 & 1 & 447 & 59.9 & 0.0002 \\
\hline & NA & mean & sd & NA & mean & sd & NA & mean & sd & $p$-value \\
\hline Last serum creatinine $(\mu \mathrm{mol} / \mathrm{l})$ & 29 & 92.5 & 58.8 & 24 & 92.1 & 57.7 & 5 & 94.6 & 64.0 & 0.3093 \\
\hline Age (years) & 15 & 54.1 & 22.1 & 14 & 53.6 & 23.2 & 1 & 56.8 & 14.3 & $<0.0001$ \\
\hline
\end{tabular}

Abbreviations: ECD Expanded Donor Criteria, CMV Cytomegalovirus, EBV Epstein-Barr Virus

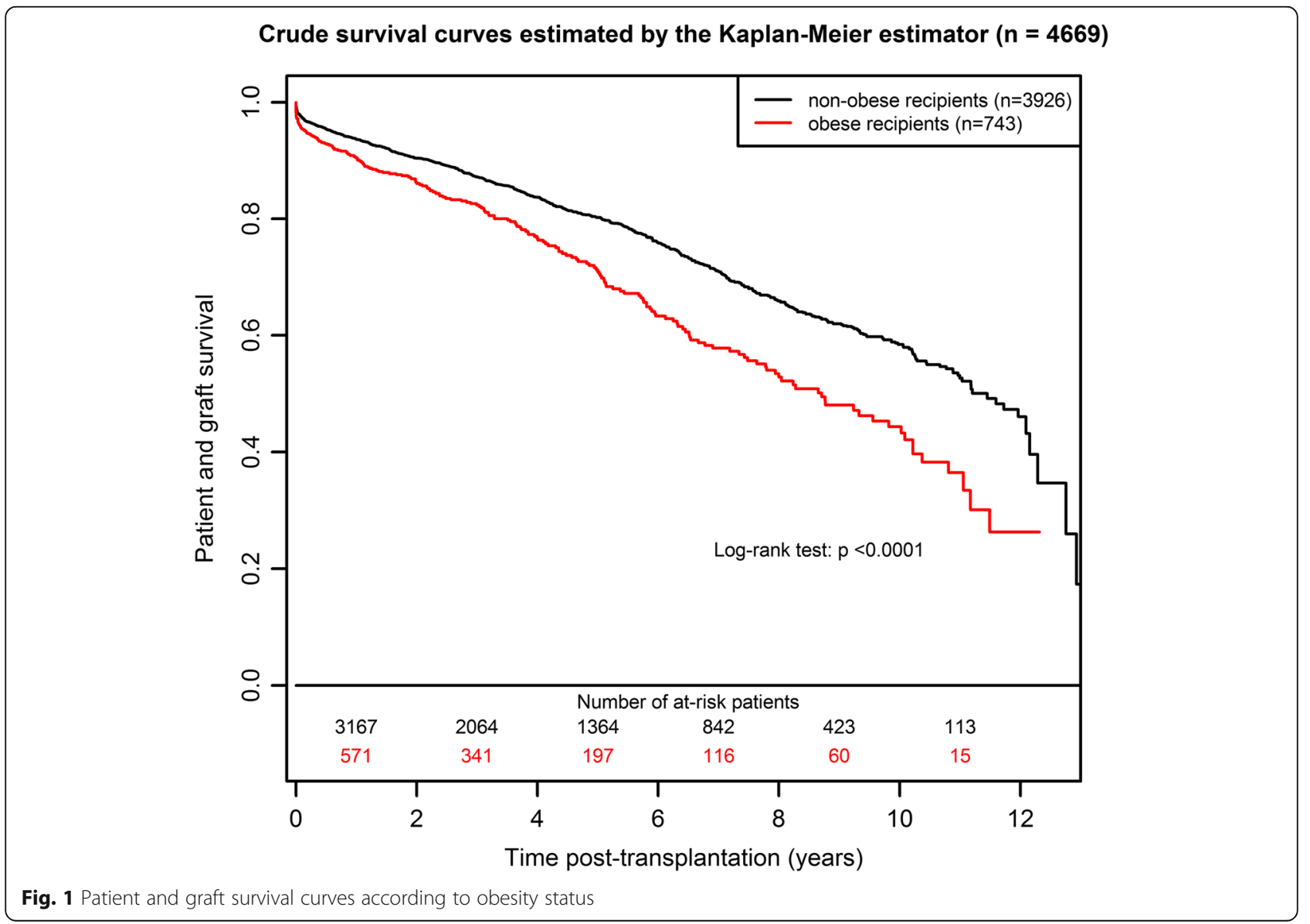




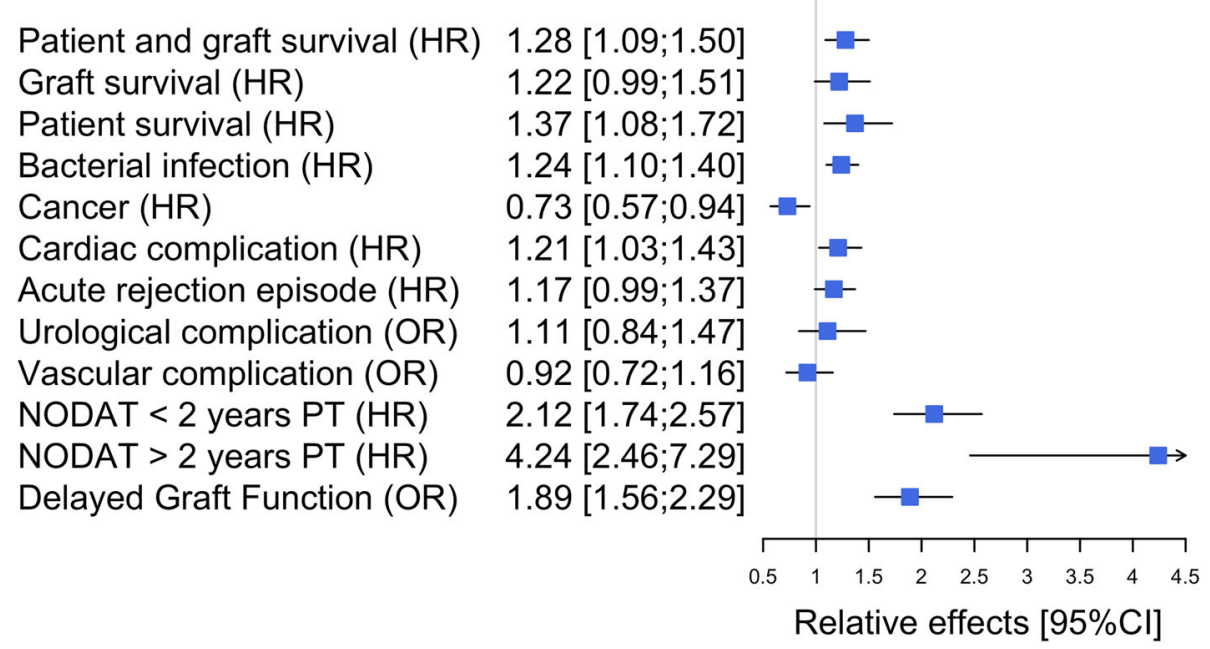

Fig. 2 Summary of adjusted relative effects of obese versus non-obese recipients

from 0.22 to 0.25 ) in the NOG versus 0.32 (95\%CI from 0.28 to 0.36 ) in the OG. The corresponding adjusted HR was 1.21 (Table S6, 95\%CI from 1.03 to $1.43, p<0.0192$ ). Finally, the cumulative probability of an acute rejection episode at 5 years post-transplantation was 0.28 (95\% CI from 0.26 to 0.29 ) in the NOG versus 0.31 (95\%CI from 0.27 to 0.35 ) in the OG. The corresponding adjusted HR for obese versus non-obese recipients was 1.17 (Table S7, 95\%CI from 0.99 to $1.37, p=0.0580$ ).

\section{Early urological surgical and vascular complications}

The overall percentage of urological surgical complications was $8.6 \%(n=402): 9.9 \%$ in the OG $(95 \% \mathrm{CI}$ from 9.0 to $10.8 \%$ ) versus $8.3 \%$ in the NOG $(95 \%$ CI from 7.5 to $9.2 \%$ ). When adjusted on possible confounders (Table S8a), no significant difference was identified ( $\mathrm{OR}=1.11$, $95 \%$ CI from 0.84 to $1.47, p=0.4443$ ). However, we observed that obese patients presented higher rates of lymphocele that required surgical intervention (48.6\%) compared to non-obese patients (36\%). In contrast, we observed less ureteral fistula in obese patients (23\% versus $35.1 \%$ respectively, Table $\mathrm{S} 8 \mathrm{~b}$ ).

Vascular complications were similar for the two groups, with $15.5 \%$ in the OG (95\%CI from 14.4 to $16.7 \%$ ) versus $14.8 \%$ in the NOG (95\%CI from 13.7 to $15.9 \%$ ). Adjusted results confirmed non-significant differences in vascular complications within the first month after the transplantation (Table S9a, OR $=0.92$, 95\%CI from 0.72 to 1.16 ). As illustrated in Table S9b, despite overall vascular complications being quite similar in the two groups, we observed that arterial thrombosis was more frequent in obese (23.3\%) compared to non-obese patients (11.6\%).
Subgroup analyses: metabolic complication and DGF For NODAT analysis, 930 patients were excluded because they were already diabetic before the transplantation. Characteristics of the 3760 studied patients are described in Table S10. Four hundred fifty-eight patients were in the OG (12.2\%) versus 3302 in the NOG $(87.8 \%)$. The cumulative probability of developing NODAT at 5 years posttransplantation was 0.17 (95\%CI from 0.16 to 0.19 ) in the NOG compared to 0.42 in the OG (95\%CI from 0.36 to 0.47). After considering possible confounders (Table S11), obese patients presented a 1.2-fold increase in the risk of NODAT within 2 years after transplantation (95\%CI from 1.74 to $2.57, p<0.0001)$. After 2 years post-transplantation, this hazard ratio increased to 4.24 (95\%CI from 2.46 to 7.29 , $p<0.0001)$.

For DGF analysis, 1005 patients were excluded because they were undergoing peritoneal dialysis or not dialyzed before transplantation, the need for dialysis in the first week post-transplantation being not evaluable for these recipients. Characteristics of the 3686 patients are described in Table S12. Six hundred fifteen patients were in the OG (16.7\%) versus 3071 in the NOG (83.3\%). We found a DGF prevalence of $26.2 \%$ (95\%CI from 24.8 to $27.6 \%$ ) in the NOG compared to $42.1 \%$ (95\%CI from 40.5 to $43.7 \%$ ) in the OG. When adjusted for possible confounders (Table S13), we confirmed that obese patients have a higher DGF susceptibility $(\mathrm{OR}=$ 1.89 ; $95 \%$ CI from 1.56 to 2.29 ; $p<0.0001$ ) compared to nonobese patients.

\section{Discussion}

Based on a French cohort, we report that obesity does not significantly increase the risk of urologic or vascular complications or graft loss, but seems to increase the 
risk of cardiac and infectious complications and the mortality.

Our results are likely to be representative of the entire French transplantation cohort since we studied more than 4500 recipients of a first kidney graft between 2005 and 2016, from a multicenter cohort gathering one third of the national transplantation activity. The proportion of obese patients in our transplantation cohort was $15.9 \%$, in-line with French practices recently described from the national French Registry. One can note that $20 \%$ of dialyzed patients in France are obese, illustrating that obesity may be an obstacle to transplantation access, as previously reported [20]. This was the main reason of our study; obese patients have a lower access to transplantation in France, whilst the risk/benefit ratio associated with transplantation remains unknown in French obese patients. The French health authority recommends limiting transplantation to recipients with a BMI below $35 \mathrm{~kg} / \mathrm{m}^{2}$ [21], and this cutoff is mainly based on North-American studies. In our cohort, only $2.4 \%$ $(n=113)$ of patients presented a BMI above $35 \mathrm{~kg} / \mathrm{m}^{2}$, meaning that the relevance of this threshold cannot be investigated due to the small sample size.

Concerning the patient demographic characteristics, we observed that obese patients presented a different profile at transplantation since they were more likely to be female, older, or with higher rates of diabetes and dyslipidemia. This could explain why they were more likely to receive an ECD donor kidney. These characteristics were considered as potential confounders in the multivariate models.

In terms of early complications, and particularly delayed graft function, our results agree with previously published findings [16, 22]. DGF is the most consensual complication observed in obese patients. This could be explained by the greater difficulty in assessing the need for dialysis in these overweight patients, resulting in an over-indication for dialysis post-transplantation. Another explanation could be a longer surgery time required for kidney implantation in obese patients which may predispose to additional complications [23]. This was not the case in our cohort since we reported similar risk of urologic and vascular complications in obese and non-obese patients. However, we only retained early complications requiring surgical intervention, which probably underestimated these events.

We also observed a trend for a higher rate of acute rejections in obese patients, possibly explained by the higher DGF rate [24], the increase in inflammation and alloimmunity and the decrease in the bioavailability of immunosuppression [25]. In addition, the increased incidence of DGF and acute rejection are in agreement with the lower patient and graft survival we observed in the obese patients. Other explanations for the increased risk of death with a functioning graft and higher risk of graft failure for the obese group are the higher incidence of NODAT, more serious bacterial infectious diseases and more cardiac complications.

We investigated whether the risks of graft failure and/or death for obese patients increased steadily with BMI. Whilst we did not observe such a trend, this may be due to sample-to-sample fluctuations caused by the small number of patients with a very high BMI. We also explored the interaction between the recipient age and BMI. In contrast to the lack of a deleterious effect of obesity observed for older patients under dialysis [17], we observed a greater risk of death and patient and graft failure due to obesity in older kidney transplant recipients.

Two North-American studies reported a beneficial effect of transplantation for obese patients with 3.3\% deaths per year compared to $6.6 \%$ for those who stayed on the waiting list $[26,27]$. Therefore, despite our finding that obesity correlates with worse short and longterm graft survival and an increased risk of death after transplantation, we could not conclude that it is preferable to maintain these patients on dialysis. Nevertheless, our results reinforce the potential benefit of helping obese transplant candidates lose weight before transplantation, for instance by using bariatric surgery [28]. Dietary intervention for obese patients with a lower BMI before transplantation remains debatable [29].

Other limitations of our study can be outlined. Firstly, obesity is also the consequence of crucial but uncontrollable factors in our cohort, including genetic considerations, social status, eating, physical activity habits and stress, which could obviously limit the interpretation of our results. Secondly, the BMI per se is a rough marker of obesity. Thirdly, additional outcomes would have been interesting to report, such as length of hospital stay or wound complications. Fourthly, for the analyses related to the DGF, we excluded the patients previously on peritoneal dialysis. This choice can be debated [30]. These patients could need dialysis in the week after the transplantation, which could be considered as delayed graft function. However, these patients often present preserved diuresis and residual glomerular filtration rate, which is associated with a lower prevalence of the DGF in this population. In contrast, because the dialysis is easier to perform in this population, it is more frequently use for their comfort. Finally, using BMI to define obesity could also be another limitation of our study, abdominal circumference or other morphometric models could be more helpful to define obesity from a surgical point of view [31]. In addition, this study did not include any robotic transplantation. This miniinvasive approach is nowadays well established, even in European centres, to decrease abdominal wound complications in obese patients [32]. 


\section{Conclusions}

In conclusion, our study provides updated results related to outcomes of French obese kidney transplant recipients. French obese patients presented a higher risk of death, serious infections and cardiac complications but not early urologic or vascular complications. The prognosis is even worse for patients who are both obese and elderly. In order to improve graft allocation procedures, epidemiological studies aimed at comparing obese kidney transplant recipients versus obese candidates staying on dialysis are needed, with specific attention to the recipient and donor characteristics that can interact with the transplantation effect.

\begin{abstract}
Abbreviations
BMl: Body mass index; Cl: Confidence interval; CMV: Cytomegalovirus; DGF: Delayed graft function; DIVAT: Données Informatisées et VAlidées en Transplantation; n: Effective; ESRD: End-stage renal disease; EBV: Epstein-Barr Virus; ECD: Expanded criteria donor; HR: Hazard ratio; HLA: Human Leucocyte Antigen; m: Mean; NA: Number of missing values; NODAT: New Onset Diabetes After Transplantation; NOG: Non-obese group; OG: Obese group; OR: Odds-ratio; HR: Hazards ratio; PTLD: Post-Transplant Lymphoproliferative Disease; sd: Standard deviation
\end{abstract}

\section{Supplementary Information}

The online version contains supplementary material available at https:/doi. org/10.1186/s12882-021-02278-1

\section{Additional file 1}

\section{Acknowledgements}

The authors would like to thank the members of the DIVAT consortium* for their involvement in the study, the physicians who helped recruit patients, and all patients who participated in this study. We also thank the clinical research associates who participated in the data collection. Data were extracted from the French DIVAT multicentric prospective cohort of kidney and/or pancreatic transplant recipients (www.divat.fr, $N^{\circ}$ CNIL 914184). The analysis and interpretation of these data are the responsibility of the authors. Données Informatisées et VAlidées en Transplantation, DIVAT Cohort Collaborators (Medical Doctors, Surgeons, HLA Biologists). Nantes: Gilles Blancho, Julien Branchereau, Diego Cantarovich, Agnès Chapelet, Jacques Dantal, Clément Deltombe, Lucile Figueres, Claire Garandeau, Magali Giral, Caroline Gourraud-Vercel, Maryvonne Hourmant, Georges Karam, Clarisse Kerleau, Aurélie Meurette, Simon Ville, Christine Kandell, Anne Moreau, Karine Renaudin, Anne Cesbron, Florent Delbos, Alexandre Walencik, Anne Devis; ParisNecker: Lucile Amrouche, Dany Anglicheau, Olivier Aubert, Lynda Bererhi, Christophe Legendre, Alexandre Loupy, Frank Martinez, Rébecca Sberro-Soussan, Anne Scemla, Claire Tinel, Julien Zuber; Nancy: Pascal Eschwege, Luc Frimat, Sophie Girerd, Jacques Hubert, Marc Ladriere, Emmanuelle Laurain, Louis Leblanc, Pierre Lecoanet, Jean-Louis Lemelle; Lyon E. Hériot: Lionel Badet, Maria Brunet, Fanny Buron, Rémi Cahen, Sameh Daoud, Coralie Fournie, Arnaud Grégoire, Alice Koenig, Charlène Lévi, Emmanuel Morelon, Claire Pouteil-Noble, Thomas Rimmelé, Olivier Thaunat; Montpellier: Sylvie Delmas, Valérie Garrigue, Moglie Le Quintrec, Vincent Pernin, Jean-Emmanuel Serre.

\section{Authors' contributions}

YF: Conceptualization, Formal analysis, Funding acquisition, Methodology, Supervision, Writing the original draft. ML: Formal analysis, Writing the original draft. SR: Formal analysis. $L A, M L, P V, C L, F B, E M, S G, M L, D G, C L, J D$, and JB: writing the original draft. CK: Data curation, Project administration. MG: Supervision, Validation, Visualization, Writing the original draft. The author(s) read and approved the final manuscript.

\section{Funding}

This work was partially supported by a public grant overseen by the French National Research Agency (ANR) to create the Common Laboratory RISCA (Research in Informatic and Statistic for Cohort Analyses, www.labcom-risca. com, reference: ANR-16-LCV1-0003-01) involving the development of PlugStat ${ }^{\oplus}$ software.

\section{Availability of data and materials}

Data from the DIVAT cohort is not publicly available. The complete procedure is explained at the DIVAT web site (http://www.divat.fr/access-todata). Briefly, the first step is to complete a collaboration form. The scientific committee then studies the project and offers a response within 30 days. If agreed, the anonymized database is sent. Otherwise, an update of the request can be referred to the board. This process may be free of charge for academic studies.

\section{Declarations}

Ethics approval and consent to participate

Data were extracted from the DIVAT cohort (French Research Ministry: RC12_0452, last agreement No 13 334, No CNIL for the cohort: 891735). The study was performed in accordance with the Declaration of Helsinki and we obtained the agreement of the DIVAT Scientific Council. The participants gave written informed consent.

\section{Consent for publication}

Not applicable

\section{Competing interests}

The authors of this manuscript have no conflict of interest to disclose for this study.

\section{Author details}

${ }^{1}$ INSERM UMR 1246 - SPHERE, Nantes University, Tours University, Nantes, France. ${ }^{2}$ Centre Hospitalier Universitaire de Nantes, Nantes, France. ${ }^{3}$ CRTI UMR 1064, Inserm, Université de Nantes; ITUN, CHU Nantes; RTRS Centaur, Nantes, France. ${ }^{4}$ Department of Nephrology and Renal Transplantation, Hospital Pasteur, Nice, France. ${ }^{5}$ Nephrology, Dialysis and Transplantation Department, Lapeyronie University Hospital, Montpellier, France. ${ }^{6}$ Kidney Transplant Center, Necker University Hospital, APHP, RTRS « Centaure », Paris Descartes and Sorbonne Paris Cité Universities, Paris, France. ${ }^{7}$ Nephrology, Transplantation and Clinical Immunology Department, RTRS «Centaure », Edouard Herriot University Hospital, Hospices Civils, Lyon, France. ${ }^{8}$ Renal Transplantation Department, Brabois University Hospital, Nancy, France. ${ }^{9}$ Department of Nephrology and Renal Transplantation, CHU Paris-GH St-Louis Lariboisière F. Widal, Paris, France. ${ }^{10}$ Centre d'Investigation Clinique en Biothérapie, Centre Hospitalier Universitaire de Nantes, Nantes, France.

Received: 9 July 2020 Accepted: 21 February 2021

Published online: 05 March 2021

\section{References}

1. Obesity and overweight. https://www.who.int/news-room/fact-sheets/detail/ obesity-and-overweight. Accessed 26 Dec 2019.

2. NCD Risk Factor Collaboration (NCD-RisC). Trends in adult body-mass index in 200 countries from 1975 to 2014: a pooled analysis of 1698 populationbased measurement studies with 19.2 million participants. Lancet Lond Engl. 2016;387:1377-96.

3. Obermayr RP, Temml C, Knechtelsdorfer M, Gutjahr G, Kletzmayr J, Heiss S, et al. Predictors of new-onset decline in kidney function in a general middle-european population. Nephrol Dial Transplant Off Publ Eur Dial Transpl Assoc - Eur Ren Assoc. 2008;23:1265-73.

4. Kramer HJ, Saranathan A, Luke A, Durazo-Arvizu RA, Guichan C, Hou S, et al. Increasing body mass index and obesity in the incident ESRD population. J Am Soc Nephrol JASN. 2006;17:1453-9.

5. Vashistha T, Mehrotra R, Park J, Streja E, Dukkipati R, Nissenson AR, et al. Effect of age and dialysis vintage on obesity paradox in long-term hemodialysis patients. Am J Kidney Dis Off J Natl Kidney Found. 2014;63: 612-22.

6. Stenvinkel $P$, Zoccali C, Ikizler TA. Obesity in CKD--what should nephrologists know? J Am Soc Nephrol JASN. 2013;24:1727-36. 
7. Wolfe RA, Ashby VB, Milford EL, Ojo AO, Ettenger RE, Agodoa LY, et al. Comparison of mortality in all patients on dialysis, patients on dialysis awaiting transplantation, and recipients of a first cadaveric transplant. $\mathrm{N}$ Engl J Med. 1999;341:1725-30.

8. Laupacis A, Keown P, Pus N, Krueger H, Ferguson B, Wong C, et al. A study of the quality of life and cost-utility of renal transplantation. Kidney Int. 1996;50:235-42

9. Knoll G, Cockfield S, Blydt-Hansen T, Baran D, Kiberd B, Landsberg D, et al. Canadian Society of Transplantation consensus guidelines on eligibility for kidney transplantation. CMAJ Can Med Assoc J J Assoc Medicale Can. 2005; 173:1181-4

10. Thuret R, Tillou X, Doerfler A, Sallusto F, Branchereau J, Terrier N, et al. Kidney transplantation in obese recipients: review of the Transplantation Committee of the French Association of Urology. Progres En Urol J Assoc Francaise Urol Soc Francaise Urol. 2012;22:678-87.

11. Gill JS, Hendren E, Dong J, Johnston O, Gill J. Differential association of body mass index with access to kidney transplantation in men and women. Clin J Am Soc Nephrol CJASN. 2014;9:951-9.

12. Lassalle M, Fezeu LK, Couchoud C, Hannedouche T, Massy ZA, Czernichow S. Obesity and access to kidney transplantation in patients starting dialysis: a prospective cohort study. PLoS One. 2017;12:e0176616.

13. Kasiske BL, Snyder JJ, Gilbertson D, Matas AJ. Diabetes mellitus after kidney transplantation in the United States. Am J Transplant Off J Am Soc Transplant Am Soc Transplant Surg. 2003;3:178-85.

14. McAdams-Demarco MA, Grams ME, Hall EC, Coresh J, Segev DL. Early hospital readmission after kidney transplantation: patient and center-level associations. Am J Transplant Off J Am Soc Transplant Am Soc Transplant Surg. 2012;12:3283-8.

15. Nicoletto BB, Fonseca NKO, Manfro RC, Gonçalves LFS, Leitão CB, Souza GC. Effects of obesity on kidney transplantation outcomes: a systematic review and meta-analysis. Transplantation. 2014;98:167-76.

16. Lafranca JA, IJermans JNM, Betjes MGH, Dor FJMF. Body mass index and outcome in renal transplant recipients: a systematic review and metaanalysis. BMC Med. 2015;13:111.

17. Hill CJ, Courtney AE, Cardwell CR, Maxwell AP, Lucarelli G, Veroux M, et al. Recipient obesity and outcomes after kidney transplantation: a systematic review and meta-analysis. Nephrol Dial Transplant Off Publ Eur Dial Transpl Assoc - Eur Ren Assoc. 2015;30:1403-11.

18. Sood A, Hakim DN, Hakim NS. Consequences of recipient obesity on postoperative outcomes in a renal transplant: a systematic review and meta-analysis. Exp Clin Transplant Off J Middle East Soc Organ Transplant. 2016:14:121-8.

19. Grèze C, Pereira B, Boirie Y, Guy L, Garrouste C, Heng A-É. Impact of obesity in kidney transplantation: Monocentric cohort study and review of the literature. Nephrol Ther. 2018;14:454-61.

20. Trébern-Launay K, Kessler M, Bayat-Makoei S, Quérard A-H, Briançon S, Giral $M$, et al. Horizontal mixture model for competing risks: a method used in waitlisted renal transplant candidates. Eur J Epidemiol. 2017.

21. Haute Autorité de Santé. www.has-sante.fr. Accessed 24 Feb 2021.

22. Molnar MZ, Kovesdy CP, Mucsi I, Bunnapradist S, Streja E, Krishnan M, et al. Higher recipient body mass index is associated with post-transplant delayed kidney graft function. Kidney Int. 2011;80:218-24.

23. Lentine KL, Delos Santos R, Axelrod D, Schnitzler MA, Brennan DC, TuttleNewhall JE. Obesity and kidney transplant candidates: how big is too big for transplantation? Am J Nephrol. 2012;36:575-86.

24. Perico N, Cattaneo D, Sayegh MH, Remuzzi G. Delayed graft function in kidney transplantation. Lancet Lond Engl. 2004:364:1814-27.

25. Heinbokel T, Floerchinger B, Schmiderer A, Edtinger K, Liu G, Elkhal A, et al. Obesity and its impact on transplantation and alloimmunity. Transplantation. 2013;96:10-6.

26. Glanton CW, Kao T-C, Cruess D, Agodoa LYC, Abbott KC. Impact of renal transplantation on survival in end-stage renal disease patients with elevated body mass index. Kidney Int. 2003;63:647-53.

27. Krishnan N, Higgins R, Short A, Zehnder D, Pitcher D, Hudson A, et al. Kidney transplantation significantly improves patient and graft survival irrespective of BMl: a cohort study. Am J Transplant. 2015;15:2378-86.

28. Yemini R, Nesher E, Winkler J, Carmeli I, Azran C, Ben David M, et al. Bariatric surgery in solid organ transplant patients: long-term follow-up results of outcome, safety, and effect on immunosuppression. Am J Transplant Off J Am Soc Transplant Am Soc Transplant Surg. 2018;18:2772-80.
29. Hossain M, Woywodt A, Augustine T, Sharma V. Obesity and listing for renal transplantation: weighing the evidence for a growing problem. Clin Kidney J. 2017; 10:703-8.

30. Bleyer AJ, Burkart JM, Russell GB, Adams PL. Dialysis modality and delayed graft function after cadaveric renal transplantation. J Am Soc Nephrol JASN. 1999;10:154-9.

31. Pinar U, Rod X, Mageau A, Renard Y, Lebacle C, Barrou B, et al. Surgical complications risk in obese and overweight recipients for kidney transplantation: a predictive morphometric model based on sarcopenia and vessel-to-skin distance. World J Urol. 2020.

32. Prudhomme $T$, Beauval JB, Lesourd $M$, Roumiguié $M$, Decaestecker $K$, Vignolini G, et al. Robotic-assisted kidney transplantation in obese recipients compared to non-obese recipients: the European experience. World J Urol. 2020

\section{Publisher's Note}

Springer Nature remains neutral with regard to jurisdictional claims in published maps and institutional affiliations.
Ready to submit your research? Choose BMC and benefit from:

- fast, convenient online submission

- thorough peer review by experienced researchers in your field

- rapid publication on acceptance

- support for research data, including large and complex data types

- gold Open Access which fosters wider collaboration and increased citations

- maximum visibility for your research: over $100 \mathrm{M}$ website views per year

At BMC, research is always in progress.

Learn more biomedcentral.com/submissions 